\title{
PENGARUH TERAPI PIJAT DAN AROMATERAPI MAWAR TERHADAP PENURUNAN NYERI MENSTRUASI PADA REMAJA PUTRI
}

\author{
Sri Ayu Arianti ${ }^{1}$, Mentari ${ }^{2}$ \\ 1,2) Universitas Bhakti kencana \\ sri.ayu@bku.ac.id
}

\begin{abstract}
ABSTRAK
Nyeri menstruasi merupakan gangguan yang sering dialami oleh sebagian besar wanita. Kebanyakan wanita mengalami tingkat kram yang bervariasi, dari tingkat nyeri ringan sampai nyeri berat. Beberapa remaja putri menderita rasa sakit yang mampu menghentikan aktivitas belajar. Terapi pijat dan aromaterapi merupakan terapi tradisional yang digunakan sejak zaman dahulu. Penelitian ini bertujuan untuk mengetahui pengaruh terapi pijat dan aromaterapi mawar terhadap penurunan nyeri menstruasi. Desain penelitian menggunakan Penelitian Analitik dengan Pendekatan Eksperimen. Sampel dalam penelitian 44 orang mahasiswi kebidanan menggunakan Teknik Random Sampling dengan kriteria inklusi remaja putri yang sedang mengalami nyeri menstruasi, belum menikah dan belum mempunyai anak. Data diperoleh dengan cara prates tingkat nyeri dengan instrumen skala penilaian, Pada kelompok eksperimen diberikan perlakuan 1 kali terapi pijat dan aromaterapi mawar selama 30 menit, kemudian dilakukan pascates untuk mengetahui penurunan tingkat nyerinya. Analisis statistik menggunakan t-test. Hasil penelitian menunjukkan bahwa skala nyeri menstruasi pascates lebih rendah dibandingkan dengan skala nyeri menstruasi prates pada kelompok perlakuan dengan $p$-value $(0,000)$, sedangkan pada kelompok kontrol tidak terdapat penurunan yang signifikan pada skala nyeri menstruasi dengan $p$-value $(0,789)$. Terdapat pengaruh terapi pijat dan aromaterapi mawar terhadap penurunan nyeri menstruasi. Hasil dari penelitian ini diharapkan dapat mengimplikasikan terapi untuk pengembangan ilmu kebidanan bagi masyarakat.
\end{abstract}

Kata kunci : aromaterapi mawar, nyeri menstruasi, terapi pijat

\begin{abstract}
Menstrual pain is a disorder that is often experienced by women. Most women experience varying levels of cramping, from mild pain levels to severe pain, while others suffer pain which can stop learning activity. Massage therapy and aromatherapy are traditional therapies that have been used since ancient times. This research is aimed to determine the effect of massage therapy and rose aromatherapy on reducing menstrual pain. The research design used an analytical study with an experimental approach. The sample in the study consisted of 44 midwifery students using random sampling technique with the inclusion criteria of woman who experience menstrual pain, were not married and had no children. The data were obtained by means of a pre-test of the level of pain with an instrument rating scale, the experimental group was given one treatment of massage therapy and rose aromatherapy for 30 minutes, then a post test was carried out to determine the decrease in the level of pain. Statistical analysis used the T-test. The results showed that the pain scale of post-test of menstrual pain was lower than the pretest in the treatment group with a p-value (0.000). Whereas in the control group, there was no significant decrease pain scales for pre-test and post-test with p-value (0.789). There is an effect of massage therapy and rose aromatherapy towards the menstrual pain. It is expected to have implications therapy for the development of midwifery science for the community.
\end{abstract}

Keywords: rose aromatherapy, massage therapy, menstruation pain 


\section{PENDAHULUAN}

Dalam perkembangan kesehatan saat ini kesehatan reproduksi wanita merupakan masalah yang cukup kompleks. Setiap wanita melewati berbagai siklus dalam pertumbuhannya yaitu mulai dari masa bayi, kanak-kanak, pubertas, reproduksi, klimakterium hingga masa senium. Perubahan dari bentuk dan fungsi tubuh wanita terjadi dalam waktu relatif cepat. Hal ini menunjukkan berkembangnya tanda seks sekunder, menyebabkan remaja secara fisik mampu melakukan fungsi proses reproduksi (Prijatni \& Rahayu, 2016).

Dalam setiap fase kehidupannya wanita juga dapat mengalami berbagai gangguan yang dapat dikatakan khas karena merupakan penyimpangan dari faal yang khas. Menstruasi atau haid adalah siklus yang akan selalu dialami setiap wanita usia subur dalam kurun usia 10 sampai 49 tahun. Dan siklus menstruasi ini akan dialami oleh wanita setiap bulannya. Menstruasi merupakan siklus yang fisiologis tetapi dapat berubah menjadi patologis apabila sudah terjadi gangguan atau masalah. Masalah menstruasi dapat berupa tidak mengalami menstruasi sama sekali sampai nyeri menstruasi berat dan berkepanjangan. (Prawirohardjo, 2016)

Nyeri menstruasi merupakan gangguan yang sering dialami oleh sebagian besar wanita. bahkan menjadi sangat menyiksa karena rasa sakit yang luar biasa. Dismenorea adalah rasa nyeri yang menyertai menstruasi/ haid. Keadaan ini dapat mengganggu aktivitas seharihari. Kebanyakan wanita mengalami tingkat kram yang bervariasi, dari tingkat nyeri ringan sampai tingkat nyeri berat. Pada beberapa wanita dismenorea muncul dalam bentuk rasa tidak nyaman ringan dan letih, namun beberapa wanita lain menderita rasa sakit yang mampu menghentikan aktivitas (Manuaba, 2016).

Nyeri menstruasi disebabkan oleh beberapa faktor, antara lain: faktor psikis, konstitusional, obstruksi kanalis servikalis dan faktor endokrin. (Prawirohardjo, 2016)

Kerja prostaglandin, zat seperti hormon yang dapat menyebabkan otot-otot rahim berkontraksi yang merupakan instrumen utama dismenorea. Kadar prostaglandin sepertinya tidak berhubungan dengan tingkat dismenorea. Hal ini terbukti pada beberapa wanita terlihat memiliki kadar prostaglandin tinggi tanpa efek samping, sementara yang lain dengan kadar normal menderita gejala yang berat. Faktor-faktor lain, termasuk perbedaan anatomi, kecenderungan genetik, dan stres, juga dapat memainkan peran.(Kusmiran, 2012) Hal ini sesuai dengan penelitian Nurul Andi tahun 2013 yang berjudul Faktor yang Berhubungan dengan Kejadian Dismenorea pada Remaja Putri di SMAN 1 Kahu Kabupaten Bone, dan penelitian Herawati tahun 2017 tentang Faktor-Faktor yang Mempengaruhi Kejadian Nyeri Haid (Dismenorea) yang mengatakan penyebab terbanyak terjadinya dismenorea dikarenakan faktor genetik yaitu riwayat keluarga yang mengalami nyeri haid (Nurul Andi, Jumriani, Ansar, 2013) (Herawati, 2017).

Nyeri menstruasi biasanya lebih sering dialami oleh remaja, dan nyeri menstruasi yang dialami remaja umumnya bukan karena penyakit (Dismenore primer)(Prawirohardjo \& Wiknjosastro, 2017). Berdasarkan penelitian Ndoen $80 \%$ dari 165 mahasiswi Fakultas Kedokteran Universitas Andalas mengalami nyeri haid primer $44,8 \%$ mengalami nyeri ringan, $12,7 \%$ nyeri sedang, dan $6,7 \%$ nyeri berat. (Ndoen et al., n.d.) Nyeri menstruasi primer pada umumnya dimulai pada bulan keenam sampai tahun ketiga setelah menarche. Nyeri menstruasi ini seringkali hilang pada usia 25 tahun atau setelah wanita hamil dan melahirkan pervaginam, disebabkan uterus mengalami istirahat dari fase menstruasi. (Prawirohardjo \& Wiknjosastro, 2017) 
Beberapa penanganan yang dilakukan untuk mengurangi dismenorea dapat dilakukan dengan pemberian obat analgetik, terapi hormonal, terapi anti prostaglandin dan dilatasi kanalis servikalis. (Prawirohardjo, 2016) Selain penanganan medis pendekatan nonfarmasi dalam mengurangi dismenorea telah bermunculan. Beberapa ahli telah banyak menemukan pengobatan di luar pengobatan medis yang disebut dengan pengobatan komplementer. (Muchtaridi \& Moelyono, 2015) Metode komplementer yang disajikan dapat berupa homeopati (misalnya, belladonna dan chamomilla), akupuntur, biofeedback, teknik relaksasi, masase, olahraga, aromaterapi (misalnya, minyak bunga mawar), dan penggunaan herbal tertentu (misalnya, black cohosh, daun raspberry, shakuyaku-kanzo-to, semen coicus, dan chaste berry)(Muchtaridi \& Moelyono, 2015).

Pengobatan tradisional bukan sekedar sebagai fenomena medis dan ekonomi, tetapi lebih luas lagi yaitu sebagai fenomena sosial budaya(Azwar, 2012b). Hal ini terjadi dalam kehidupan masyarakat, terutama kehidupan yang menyangkut kesehatan individu ataupun masyarakat. Pengobatan dan obat tradisional telah menyatu dengan masyarakat digunakan dalam mengatasi berbagai masalah kesehatan baik di desa maupun di kota. Kemampuan masyarakat untuk mengobati sendiri, mengenal gejala penyakit, dan memelihara kesehatan perlu ditingkatkan dalam rangka mencapai kesehatan bagi semua. Dewasa ini pengobatan dengan cara - cara tradisional semakin populer baik di dalam negeri maupun di luar negeri.

Aromaterapi adalah istilah lain dari minyak esensial yang mempunyai aroma serta berguna sebagai terapi. Jenis minyak aroma ini diekstraksi dari bunga mawar. Karakteristik dari essensial oil mawar memiliki aroma yang manis, lembut, dan bernuansa cantik. Karena produknya memiliki aroma yang lembut, menyebarkan wanginya ke seluruh ruangan. Hal ini dapat mengurangi tingkat stres, menumbuhkan perasaan tenang pada jasmani, pikiran, dan rohani dan meningkatkan mood. Wanita dalam keadaan haid sering kali mengalami penurunan mood atau minat sehingga dapat mengganggu aktivitas sehari-hari.

Sebagai tambahan, aromaterapi mawar juga dapat digunakan dengan cara pemijatan atau masase dengan minyak esensial mawar ini memiliki efek analgesik lokal dan antispasmodik untuk mengurangi rasa tidak nyaman atau nyeri. Pijatan yang ringan dan melingkar dengan menggunakan jari pada perut bagian bawah akan membantu mengurangi nyeri menstruasi.

Beberapa minyak esensial yang sudah diteliti terbukti efektif sebagai sedatif, penenang ringan yang berfungsi menenangkan sistem saraf pusat yang dapat membantu mengatasi stres, gelisah, ketegangan, dan depresi(Kushariyadi \& Setyoadi, 2011). Kandungan minyak asiri (Essential Oil) adalah hormon, antibiotik, thermions (aroma tak terlihat) dan sel-sel daur ulang (penting untuk keberadaan tanaman). Karena sifat dari minyak inilah penggunaan sebagai terapi tradisional terhadap berbagai penyakitmeningkat. Bakteri dan virus dihilangkan dan dinetralkan. Dengan mengambil minyak asiri yang berharga dari tanaman, kita dapat menggunakan sifat pengobatan yang sama untuk memperbaiki kondisi tubuh kita(Muchtaridi \& Moelyono, 2015).

Menurut jurnal Hikmah pemberian masase effleurage menggunakan minyak aromaterapi mawar dapat menurunkan intensitas nyeri menstruasi pada remaja putri di SMK Negeri 2 Malang. (Hikmah et al., n.d.)

Regina Pratjna Pramita membuktikan dengan penelitian bahwa terdapat perbedaan perubahan intensitas nyeri sebelum dan sesudah diberikan aroma terapi mawar pada ibu bersalin kala I fase aktif di BPM Patmi Hartati Kabupaten 
Kediri. Hal ini dikarenakan kandungan yang terdapat di dalam ekstrak aromaterapi mawar yang dipanaskan dengan tungku pemanas menguap sehingga tercium aroma wangi yang menimbulkan efek tenang, merelaksasi pikiran, menyegarkan, dan menurunkan ketengangan otot pada ibu bersalin kala I fase aktif (Regina Pratjna Pramita et al., 2017). Adapun Ardela menggunakan aromaterapi mawar dengan cara relaksasi nafas dan terbukti dapat meredakan nyeri dismenorea primer(Ardela et al., 2017).

Berdasarkan studi pendahuluan dengan metode wawancara, mahasiswi prodi Kebidanan Universitas Bhakti Kencana yang memiliki masalah nyeri menstruasi sekitar 58\% dari 134 mahasiswi. Para mahasiswi sering mengeluh dengan gangguan haid tersebut hingga menggangu aktivitas sehari-hari termasuk kegiatan belajar.

Penelitian ini bertujuan untuk mengetahui pengaruh terapi pijat dan aromaterapi mawar terhadap penurunan nyeri menstruasi. Penelitian ini diharapkan memberikan manfaat untuk pengembangan ilmu pengetahuan kebidanan tentang manfaat obat herbal dalam penurunan nyeri menstruasi.

\section{METODOLOGI}

Rancangan penelitian yang digunakan pada penelitian ini adalah Rancangan Eksperimen Semu (Quasi-Experiment). Eksperimen adalah eksperimen yang memiliki perlakuan (treatments), pengukuran-pengukuran dampak (outcome measures), dan unit-unit eksperimen (experimental units), namun tidak menggunakan penempatan secara acak (random assignment) dalam menciptakan pembandingan untuk menyimpulkan adanya perubahan akibat perlakuan. (Azwar, 2012a)

Populasi dalam penelitian ini adalah seluruh mahasiswi tingkat I di Prodi D III Kebidanan Bhakti Kencana Bandung yang mengalami dismenorea sebanyak 78 orang.

Untuk populasi yang berjumlah di bawah 10.000 dengan tingkat kepercayaan 90\% dan tingkat penyimpangan $10 \%$ maka didapat besar sampel sebagai berikut. (Notoatmodjo, 2010)

$$
n=\frac{\mathrm{N}}{1+\mathrm{N}(\mathrm{d})^{2}}
$$

Sampel pada penelitian ini berjumlah 44 orang dengan menggunakan Teknik Random Sampling dengan kriteria inklusi remaja putri yang sedang mengalami nyeri menstruasi, berumur 18-21 tahun, belum menikah dan belum mempunyai anak. Dalam pelaksanaan penelitian ini menggunakan kelompok kontrol berjumlah 22 orang dan kelompok eksperimen berjumlah 22 orang.

Data diperoleh dengan cara seluruh responden diwawancara tingkat nyeri prates dan pascates dengan instrumen skala penilaian (rating scale), skala penelitian yang digunakan pada penelitian ini yaitu skala nyeri dari 1-10 (Smeltzer \& Brenda G Bare, 2013). Pada kelompok eksperimen responden diberikan perlakuan pijatan dengan minyak esensial mawar selama 30 menit oleh peneliti dan terapi inhalasi aromaterapi mawar yang dibakar menggunakan cawan kecil selama pemijatan. Kemudian dilakukan analisis statistik menggunakan t-test untuk menguji efektivitas terapi pijat dan aromaterapi mawar terhadap penurunan nyeri menstruasi. 
HASIL

Tabel 1. Distribusi Frekuensi Perbedaan Skala Nyeri Penurunan Nyeri Menstruasi Prates dan Pascates pada Grup Perlakuan

\begin{tabular}{|c|c|c|c|c|c|c|c|c|}
\hline \multirow{3}{*}{ Test } & \multicolumn{6}{|c|}{ Skala Nyeri } & \multirow{3}{*}{ Jumlah } & \multirow{3}{*}{$\%$} \\
\hline & \multicolumn{2}{|c|}{ Berat } & \multicolumn{2}{|c|}{ Sedang } & \multicolumn{2}{|c|}{ Ringan } & & \\
\hline & $\mathbf{n}$ & $\%$ & $\mathrm{n}$ & $\%$ & $n$ & $\%$ & & \\
\hline Prates & 3 & 13,6 & 17 & 77,3 & 2 & 9,1 & 22 & 100 \\
\hline Pascates & 0 & 0 & 1 & 4,5 & 21 & 95,5 & 22 & 100 \\
\hline Total & & & & & & & 44 & 100 \\
\hline
\end{tabular}

Berdasarkan tabel 1 diketahui bahwa skala nyeri menstruasi pascates lebih rendah dari pada skala nyeri dismenorea prates pada grup perlakuan. Pada prates yang mengalami nyeri berat sebanyak 3 responden atau $(13,6 \%)$, kemudian sebanyak 17 responden atau $(77,3 \%)$ nyeri sedang dan sisanya mengalami nyeri ringan sebanyak 2 responden atau $(9,1 \%)$, dan pada pascates tidak ada yang mengalami nyeri berat, kemudian sebanyak 1 responden atau $(4,5 \%)$ nyeri sedang, dan sisanya mengalami nyeri ringan sebanyak 21 responden atau $(95,5 \%)$.

Tabel 2. Distribusi Frekuensi Perbedaan Skala Nyeri Penurunan Nyeri Menstruasi Prates dan Pascates pada Grup Kontrol

\begin{tabular}{|c|c|c|c|c|c|c|c|c|}
\hline \multirow{3}{*}{ Test } & \multicolumn{6}{|c|}{ Skala Nyeri Penurunan Nyeri Menstruasi } & \multirow{3}{*}{ Jumlah } & \multirow{3}{*}{$\%$} \\
\hline & \multicolumn{2}{|c|}{ Berat } & \multicolumn{2}{|c|}{ Sedang } & \multicolumn{2}{|c|}{ Ringan } & & \\
\hline & $\mathbf{n}$ & $\%$ & $\mathbf{n}$ & $\%$ & n & $\%$ & & \\
\hline Prates & 2 & 9,1 & 16 & 72,7 & 4 & 18,2 & 22 & 100 \\
\hline Pascates & 2 & 9,1 & 16 & 72,7 & 4 & 18,2 & 22 & 100 \\
\hline Total & 2 & 4,5 & 17 & 38,6 & 25 & 56,8 & 44 & 100 \\
\hline
\end{tabular}

Berdasarkan tabel 2 diketahui bahwa pada grup kontrol tidak ada penurunan yang bermakna atau tidak ada perbedaan yang bermakna pada prates yang mengalami nyeri ringan sebanyak 4 responden atau (18,2\%), kemudian sebanyak 16 responden atau $(72,7 \%)$ nyeri sedang, dan sisanya sebanyak 2 responden atau $(9,1 \%)$ mengalami nyeri berat, dan pada pascates didapat hasil yang sama dengan prates.

Tabel 3. Pengaruh Terapi Pijat dan Aromaterapi Mawar Terhadap Penurunan Nyeri Menstruasi pada Kelompok Perlakuan dan Kelompok Kontrol

\begin{tabular}{lccccc}
\hline \multirow{2}{*}{ Kel } & \multicolumn{3}{c}{$\begin{array}{c}\text { Skala Nyeri Penurunan } \\
\text { Nyeri Menstruasi }\end{array}$} & \multirow{2}{*}{ Keterangan } & Signifikan \\
\cline { 2 - 4 } & Prates & Pascates & Selisih & & \\
\hline Perlakuan & 4,8 & 1,6 & 3,2 & Menurun & 0,000 \\
Kontrol & 4,8 & 4,9 & 0,1 & Meningkat & 0,789 \\
\hline
\end{tabular}


Berdasarkan tabel 3 hasil analisis tabel bahwa rata-rata skala penurunan nyeri menstruasi prates pada kelompok kontrol adalah 4,8 dan pascates 1,6 dengan selisih 3,2, keterangan menurun dengan signifikan $0.000<\alpha(0,05)$ dan pada kelompok kontrol didapat rata-rata skala pengurangan dismenorea prates 4,8 dan pascates 4,9 dengan selisih 0,1 , keterangan meningkat dengan signifikan $0,789>\alpha(0,05)$.

\section{PEMBAHASAN}

Hasil analisis dengan $t$-test berpasangan sig. $>\alpha(0,789)>0,05$, menunjukkan skala nyeri penurunan nyeri menstruasi pascates tidak menunjukkan perubahan yang bermakna dibandingkan dengan prates pada kelompok kontrol. Adapun pada kelompok perlakuan. hasil analisis $t$-test berpasangan sig. $<\alpha(0,000)$ $<0,05)$, menunjukkan skala nyeri pengurangan dismenorea pascates lebih rendah dari pada prates. Hal ini menunjukkan terdapat pengaruh terapi pijat dan aromaterapi mawar terhadap penurunan nyeri menstruasi dengan p-value $(0,000)$ lebih kecil dari nilai $\alpha(0,05)$. Terapi pijat berupa usapan yang lembut dapat mengurangi hipoksia pada jaringan sehingga kadar oksigen pada jaringan meningkat yang menyebabkan nyeri menstruasi berkurang. Selain itu, masase atau pijat juga dapat meningkatkan pelepasan hormon endorfin sehingga ambang nyeri dapat meningkat. Salah satu teknik pijat yang efektif dalam mengurangi nyeri menstruasi adalah pijat aromaterapi. Melalui pengobatan aromaterapi, kandungan dari minyak esensial yang memiliki daya penyembuhan dapat lebih optimal dengan dipadukan antara metode pijat menggunakan minyak esensial mawar dan inhalasi atau menghirup aroma bunga mawar untuk diserap oleh organ tubuh yang memerlukan perawatan. Setelah responden menghirup aromaterapi mawar yang dibakar dalam cawan kecil terbukti dapat mengurangi tingkat stres, menumbuhkan perasaan tenang pada jasmani, pikiran, dan rohani dan meningkatkan mood. Melalui sistem sirkulasi, aromaterapi bekerja melalui fungsi humoral (cairan tubuh), seperti darah dan kelenjar-kelenjar, yang selanjutnya akan merangsang fungsi hormonal di dalam tubuh. Sistem hormonal bekerja sama dengan sistem saraf untuk mengontrol dan mengoordinasikan aktivitas organ tubuh manusia.

Dismenorea merupakan rasa nyeri yang menyertai menstruasi. Keadaan ini pada sebagian remaja putri dapat mengganggu aktivitas kehidupan sehari-hari seperti perkuliahan. Reaksi nyeri yang ditimbulkan pada remaja dapat berbeda-beda sesuai dengan respons tubuh, dimulai dari meringis, meremas benda di sekitar bahkan sampai menangis. Kejadian dismenorea dapat dipengaruhi beberapa faktor diantaranya yaitu: faktor kejiwaan atau stres, faktor konstitusi, faktor obstruksi kanalis servikalis atau karena faktor endokrin.(Prawirohardjo, 2016)

Penurunan skala nyeri menstruasi pascates pada kelompok perlakuan menjadi berkurang dibandingkan pada kelompok kontrol disebabkan oleh pemberian aromaterapi mawar pada kelompok perlakuan secara dipijat pada daerah bawah perut(rahim) denganjari-jari tangan secara melingkar yang menyebabkan relaksasi pada otot-otot rahim yang tegang dan kombinasi aromaterapi mawar yang menenangkan dan berkhasiat mengurangi kram dan nyeri sehingga dapat menurunkan rasa nyeri saat menstruasi. Pijat telah terbukti sangat bermanfaat dalam meredakan ketegangan dan stres yang dapat memengaruhi sistem saraf dengan efektif dan tenang, respons melawan atau meredakan sehingga mengurangi tingkat hormon stres yang berbahaya dalam tubuh, pijat merangsang sirkulasi darah, akan bertambah pasokan nutrisi dan oksigen ke sel, pijat juga merangsang aliran limfatik sehingga meningkatkan sirkulasi jaringan dan sistem kekebalan tubuh. 
Aromaterapi mawar disini yang digunakannya yaitu minyak esensial mawar, minyak esensial terdapat dalam suatu kantung kecil yang terletak di antara dinding sel tumbuhan. Mawar (Rosa centifolia) berasal dari bagian bunga dan kelopak bunga dapat menyeimbangkan fungsi-fungsi tubuh, membangkitkan semangat, memperbaiki suasana hati (relaksasi), menenangkan, antidepresan. Bersifat sebagai antidepresan, bersifat sebagai antioksidan dan penguat jantung. Osnom adalah gugus steroid yang menghasilkan bau dari aromaterapi mawar yang mempunyai potensi sebagai penenang kimia alami yang akan merangsang neurokimia otak. Bau yang menenangkan akan menstimulasi talamus untuk mengeluarkan enkefalin. Minyak esensial ini dilepaskan dan beredar ke seluruh bagian tanaman untuk mengantarkan pesan yang membantu tumbuhan menjalankan fungsinya secara efisien. Jadi, minyak esensial bisa juga disebut sebagai hormonnya tanaman.

Hal ini sesuai dengan penelitian Permatasari mengatakan pemberian aromaterapi mawar dapat menurunkan tingkat nyeri pada pasien pasca operasi fraktur ekstremitas.. (Permatasari, n.d.)

Adapun Handayani melakukan aplikasi aromaterapi mawar ini pada ibu bersalin dan membuktikan bahwa terdapat perbedaan pengaruh aromaterapi mawar dengan massage effleurage terhadap penurunan rasa nyeri pada ibu bersalin.(Handayani et al., 2018) Dikutip dari jurnal Ndoen yang mengatakan bahwa aromaterapi yang dicampurkan ke dalam minyak essensial oil mawar yang mengandung analgesik dan sedatif dapat lebih memberikan khasiat yang efektif dalam mengurangi tingkat nyeri haid primer (Ndoen et al., n.d.). Adapun Sadeghi Aval Shahr membandingkan pada tiga kelompok dengan intervensi pijat dengan menggunakan minyak mawar dan minyak almond, dan didapatkan hasil pijat dengan aromaterapi terbukti dapat mengurangi tingkat keparahan dismenorea primer, dibandingkan dengan terapi pijat saja (Sadeghi Aval Shahr et al., 2015)the menstrual pain was significantly lower in the rose oil group than in the other two groups after intervention (between massage with rose oil, almond oil $\mathrm{p}=0.003$ and massage with rose oil and just massage $\mathrm{p}=0.000$.

\section{SIMPULAN DAN SARAN}

\section{Simpulan}

Simpulan dalam penelitian ini menunjukkan bahwa skala nyeri dismenorea pascates lebih rendah dibandingkan dengan skala nyeri dismenorea prates pada kelompok perlakuan dengan $p$-value $(0,000)$. Adapun pada kelompok kontrol tidak terdapat penurunan yang signifikan pada skala nyeri dismenorea prates dan pascates dengan $\mathrm{p}$-value $(0,789)$.

Dengan demikian, dapat disimpulkan bahwa terdapat pengaruh aromaterapi mawar terhadap pengurangan dismenorea dengan $p$-value $(0,000)$ lebih kecil dari nilai $\alpha(0,05)$.

\section{Saran}

Diharapkan peneliti lain dapat mengeksplorasi lagi dengan metode lain dari terapi komplementer seperti metode akupresurre dan akupuntur dalam mengurangi nyeri menstruasi sebagai implikasi pengembangan ilmu kebidanan, keperawatan, dan pendidikan kesehatan masyarakat.

\section{DAFTAR PUSTAKA}

Ardela, M., Yuliwar, R., \& Dewi, N. (2017). Efektifitas Relaksasi Nafas Dalam Dan Relaksasi Aromaterapi Bunga Mawar Terhadap Perubahan Nyeri Pada Remaja Yang Mengalami Dysmenorrhea Primer Di Kecamatan Lowokwaru Malang. In 
Nursing News (Vol. 2).

Azwar. (2012a). Metode Penelitian. Pustaka Pelajar.

Azwar, A. (2012b). Tanaman obat Indonesia. Salemba Medika.

Handayani, R. S., Mintarsih P, W., Rohmatin, E., Studi, P., Iv, D., Poltekkes, K., Tasikmalaya, K., Cilolohan, J., 35, N., \& Barat, J. (2018). Perbandingan Pengaruh Aromaterapi Mawar Dan Massage Effleurage Terhadap Nyeri Persalinan Kala I Fase Aktif. In Jurnal Bidan "Midwife Journal (Vol. 4, Issue 02). www.jurnal.ibijabar.org

Herawati, R. (2017). Faktor-Faktor Yang Mempengaruhi Kejadian Nyeri Haid (Dismenorea) Pada Siswi Madrasah Aliyah Negeri Pasir Pengaraian. DIII Kebidanan UPP, 161-172. http://ejournal.upp.ac.id/index.php/akbd/article/ view/1382

Hikmah, N., Rizky Amelia, C., \& Ariani, D. (n.d.). Pengaruh Pemberian Masase Effleurage Menggunakan Minyak Aromaterapi Mawar terhadap Penurunan Intensitas Nyeri Dismenore pada Remaja Putri di SMK Negeri 2 Malang Jurusan Keperawatan OPEN ACCESS.

Kushariyadi, \& Setyoadi. (2011). Terapi Modalitas Keperawatan Pada Klien Psikogeriatrik. Salemba Medika.

Kusmiran, E. (2012). Kesehatan Reproduksi Remaja dan Wanita. Salemba Medika.

Manuaba, I. B. G. (2016). Ilmu Kebidanan Penyakit dan Kandungan dan KB untuk Pendidikan Bidan. EGC.

Muchtaridi, \& Moelyono. (2015). Aromaterapi. Graha Ilmu.

Ndoen, M. C. P., Djajanti, C. W., Kristianingsih, Y., Katolik, S., Vincentius, S., \& Surabaya, P. (n.d.). Pengaruh Aromaterapi Mawar Terhadap Penurunan Tingkat Nyeri Haid
Primer Pada Mahasiswa.

Notoatmodjo, S. (2010). Metodologi Penelitian Kesehatan. Rineka Cipta.

Nurul Andi, Jumriani, Ansar, S. D. (2013). Faktor Yang Berhubungan Dengan Kejadian Dismenorea Pada Remaja Putri Di SMA N 1 Kahu Kabupaten Bone, 1-12.

Permatasari, E. D. (n.d.). Pengaruh Aromaterapi Mawar Terhadap Tingkat Nyeri Post Operasi Fraktur Ekstremitas Di RS Ortopedi Prof. Dr. R. Soeharso Surakarta. Disusun sebagai salah satu syarat menyelesaikan Program Studi Strata 1.

Prawirohardjo, S. (2016). Ilmu Kebidanan (ke 4). PT Bina Pustaka Sarwono Prawirohardjo.

Prawirohardjo, S., \& Wiknjosastro. (2017). Ilmu Kandungan (ketiga). PT Bina Pustaka Sarwono Prawirohardjo.

Prijatni, I., \& Rahayu, S. (2016). Kesehatan Reproduksi dan Keluarga Berencana. Pusdik SDM Kesehatan.

Regina Pratjna Pramita, D., Siti Nur Rahmawati, R., Dwi Antono Prodi Kebidanan Kediri Poltekkes Kemenkes Malang J1 Wakhid Hasyim, S. K., \& Kediri, B. (2017). Perbedaan Intensitas Nyeri Tehnik Pemberian Kompres Air Hangat Dan Aroma Terapi Mawar Pada Ibu Bersalin Kala I Fase Aktif. Jurnal Ilmu Kesehatan, 6(1), 90.

Sadeghi Aval Shahr, H., Saadat, M., Kheirkhah, M., \& Saadat, E. (2015). The effect of selfaromatherapy massage of the abdomen on the primary dysmenorrhoea. Journal of Obstetrics and Gynaecology: The Journal of the Institute of Obstetrics and Gynaecology, 35(4), 382-385. https:// doi.org/10.3109/01443615.2014.958449

Smeltzer, S. C., \& Brenda G Bare. (2013). Buku Ajar keperawatan Medikal Bedah Brunner \& Suddarth (8th ed.). EGC. 